\title{
Preface
}

\section{Near surface geophysics for the study and the management of historical resources: past, present and future (EGU GI9 Session 2009)}

\author{
L. V. Eppelbaum ${ }^{1}$, N. Masini $^{2}$, and F. Soldovieri ${ }^{3}$ \\ ${ }^{1}$ Dept. of Geophysics and Planetary Sciences, Raymond and Beverly Sackler Faculty of Exact Sciences, Tel Aviv University, \\ Tel Aviv 69978, Israel \\ ${ }^{2}$ Istituto per i Beni Archeologici e Monumentali, Consiglio Nazionale delle Ricerche, Tito Scalo, Italy \\ ${ }^{3}$ Istituto per il Rilevamento Elettromagnetico dell'Ambiente, Consiglio Nazionale delle Ricerche, 80124 Napoli, Italy
}

This special volume of ADGEO hosts papers that were presented at the session entitled "Near surface geophysics for the study and the management of historical resources: past, present and future", organized within the framework of the General Assembly of the European Geosciences Union (EGU), held in Vienna, Austria, 19-24 April 2009. As the conveners, we invited the contributors to this session to prepare papers reflecting their presentations and submit them for publication in this special volume. Two independent anonymous experts reviewed all the papers involved to this process.

The papers presented in this volume are concerned with the state of art and novel instrumentation, sensing techniques, as well as data processing approaches to support the archaeological research and Cultural Heritage conservation strategies.

In this field, in the recent years is observed an increasing of interest to non-destructive and non-invasive geophysical test methods. This allows overcoming the subjectivity and ambiguity arising in the choice of the number and the areas locations where to perform the destructive examination. In addition, non invasive techniques such as aerial and satellite remote sensing are able to give a global vision of the heritage from the identification of unknown archaeological features to the monitoring of cultural resources.
Very recently, large attention is posed to the integration of the classical geophysical techniques with new emerging surface and subsurface sensing techniques (optical sensors, thermography, acoustics) for a multi depth, multi-resolution, and multi-scale monitoring of buildings and artifacts.

We hope that the presented research papers will be interesting for readers in the different branches of the Environmental and Cultural Heritage Sciences and will attract new potential contributors to the important topic of the Cultural Heritage monitoring and diagnostics.

We wish to thank all the authors for their presentations and fruitful discussions at the session and preparing the publications. To all reviewers, without significant work of which, the publication of this volume would not have been possible. We also thank the staff of Copernicus Publications (first of all - Nadine Deisel and Svenja Lange) for their professional and friendly collaboration.

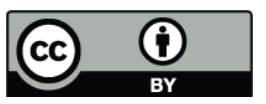

Correspondence to: N. Masini

(n.masini@ibam.cnr.it)

Published by Copernicus Publications on behalf of the European Geosciences Union. 